\title{
Supramolecular helical porphyrin arrays using DNA as a scaffold
}

Imenne Bouamaied, ThaoNguyen Nguyen, Thomas Rühl and Eugen Stulz

School of Chemistry, University of Southampton, Southampton UK SO17 1BJ. Email:est@soton.ac.uk

Please cite this paper as:

Organic \& Biomolecular Chemistry, 2008, 3888-3891

The publisher's version of this paper is available here: http://dx.doi.org/10.1039/b813584c

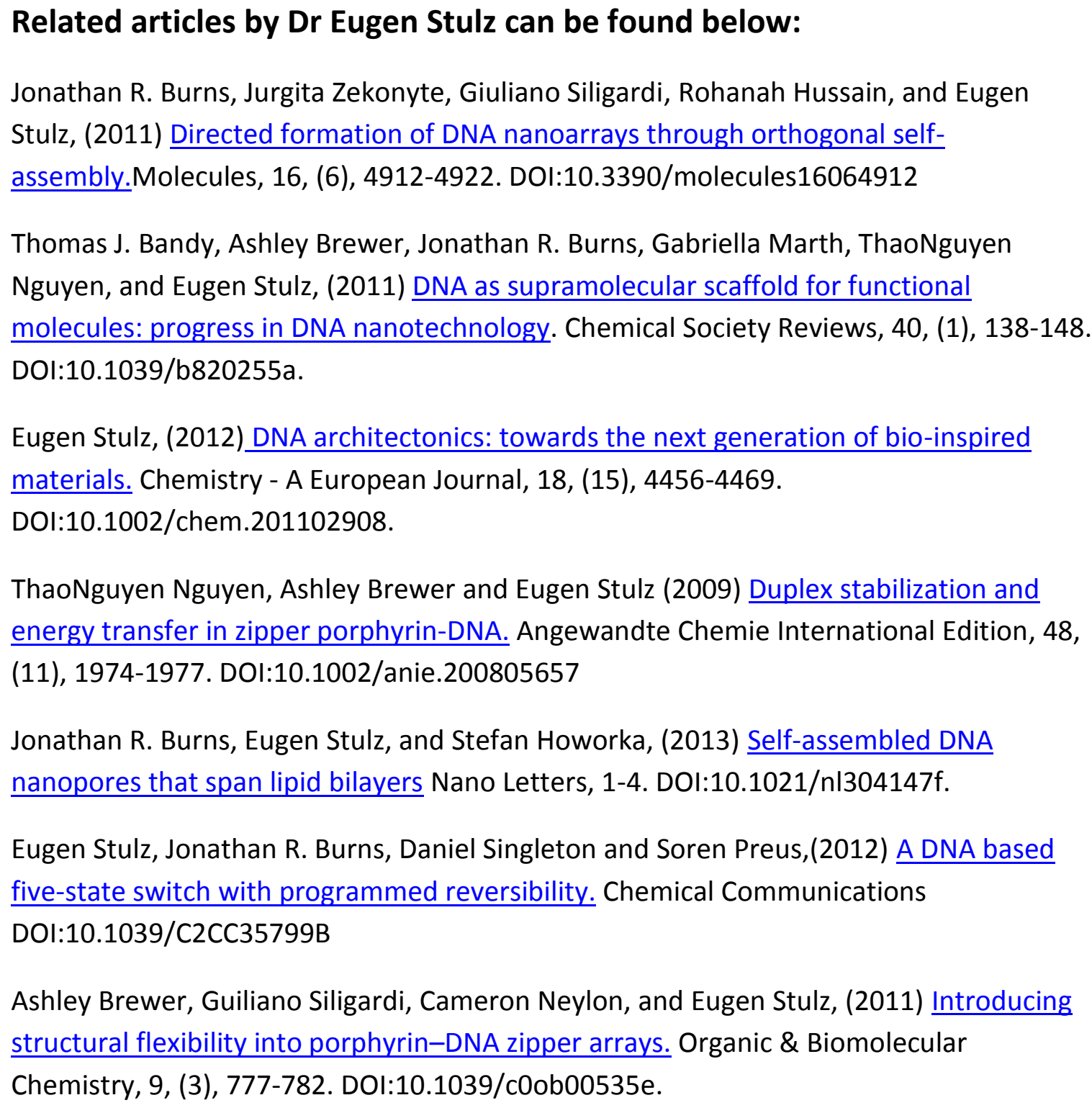




\title{
Supramolecular helical porphyrin arrays using DNA as a scaffold $\dagger$
}

\author{
Imenne Bouamaied, ThaoNguyen Nguyen, Thomas Rühl and Eugen Stulz*
}

\author{
Received 5th August 2008, Accepted 12th September 2008 \\ First published as an Advance Article on the web 22nd September 2008 \\ DOI: $10.1039 / b 813584 c$
}

\begin{abstract}
A diphenyl porphyrin substituted nucleotide was incorporated site specifically into DNA, leading to helical stacked porphyrin arrays in the major groove of the duplexes. The porphyrins show an electronic interaction which is significantly enhanced compared to the analogous tetraphenyl porphyrin (TPP) as shown in the large exciton coupling of the porphyrin B-band absorbance. Analogous to the TPPDNA, an induced helical secondary structure is observed in the single strand porphyrin-DNA. The modified DNA can be hybridised to an immobilised complementary strand leading to fluorescent beads.
\end{abstract}

DNA has recently become very attractive as a supramolecular scaffold for creating functional molecules. ${ }^{1}$ The covalent attachment of electronically active molecules such as metal complexes or organic chromophores is most conveniently done at either the nucleobase or the ribose moiety, and the substituents are normally located in the major groove of the double helix. ${ }^{2}$ Replacement of the nucleobase, on the other hand, with aromatic entities or metal complexes leads to arrays where the substituents are placed in the interior of the DNA. ${ }^{3}$ We are in the course of exploring the use of DNA as a supramolecular scaffold to create helical multiporphyrin arrays, where the porphyrins are attached covalently to the nucleobase deoxy-uridine via a rigid acetylene spacer (Fig. 1). ${ }^{4}$ We have recently shown that up to eleven tetraphenyl porphyrins can be attached to the DNA, which is the highest number of modifications with a large substituent to date. ${ }^{5}$ Other work in the field was concerned with the postsynthetic modification of DNA with porphyrins to create bundles, ${ }^{6}$ direct replacement of the nucleobase with a porphyrin, ${ }^{7}$ use of porphyrins as chirality markers ${ }^{8}$ or creation of di-porphyrin arrays through hybridisation. ${ }^{9}$ Here, we report on the synthesis and

School of Chemistry, University of Southampton, Highfield, Southampton, UK, SO17 1BJ. E-mail: est@soton.ac.uk; Fax: +44-(0)23 805968 05; Tel: +44-(0)2380599369

$\dagger$ Electronic supplementary information (ESI) available: Synthesis of $\mathbf{1}$ to 6, full spectroscopic characterisation and molecular modelling of the DPP-DNA strands. See DOI: 10.1039/b813584c

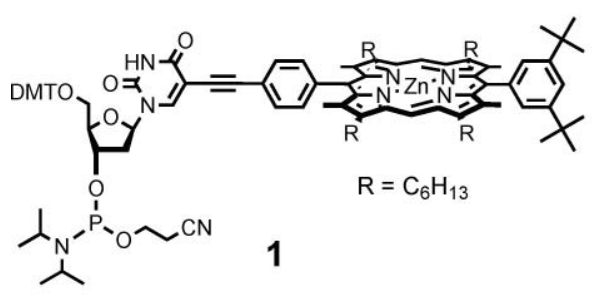

characterisation of oligo-deoxy nucleotides (ODNs) containing various numbers of diphenyl porphyrins (DPP) and in different sequences. The thus obtained DPP-DNA arrays show a strong electronic coupling between the porphyrins due to the stacking along the DNA backbone, which is much more pronounced than in the analogous tetraphenyl porphyrin (TPP) counterparts.

The building block dU ${ }^{\mathrm{ZnDPP}} \mathbf{1}$ is readily accessible via Sonogashira coupling ${ }^{10}$ between the acetylene porphyrin and $5^{\prime}$-DMT protected 5-iodo deoxy-uridine and subsequent phosphitylation. $\dagger$ Site specific incorporation of $\mathbf{1}$ into ODN strands $\mathbf{2}$ to $\mathbf{6}$ was achieved using standard phosphoramidite solid phase synthesis in a DNA synthesizer with an increased coupling time for $\mathbf{1}$ to ten minutes; purification of the modified ODNs using fluorous tag affinity chromatography ${ }^{11}$ yielded the pure strands. Thermal denaturing with the corresponding unmodified complementary strands (Table 1) were measured using both UV-vis and CD spectroscopy. The $T_{\mathrm{m}}$ values obtained from the first derivatives of the UV-melting curve $(260 \mathrm{~nm})$ and of the CD-melting curve (at $252 \mathrm{~nm}$ ) agree well. A large destabilisation of the duplex with $\Delta T_{\mathrm{m}}=-21.1^{\circ} \mathrm{C}$ was measured for one porphyrin modification in the duplex $2 \cdot 7$. In the two-porphyrin duplex $3 \cdot 7$, the destabilisation per porphyrin is much smaller with $\Delta T_{\mathrm{m}, \mathrm{P}}=-13.3^{\circ} \mathrm{C}$. When more than two porphyrins are adjacent to each other as in $\mathbf{4 \cdot 7}$, the destabilisation is only $-7.1{ }^{\circ} \mathrm{C}$ per porphyrin. It thus seems that the hydrophobic interactions between the porphyrins compensate significantly for the unfavourable steric effects. In fact, $\mathbf{4 . 7}$ has a higher melting temperature than 3.7. A similar levelling of the destabilisation was observed with the TPP analogues, but there a significantly smaller destabilisation $\left(\Delta T_{\mathrm{m}, \mathrm{P}}=-3.1{ }^{\circ} \mathrm{C}\right)$ was measured. ${ }^{5}$ To test whether a levelling of the destabilisation effect can be observed, strand $\mathbf{5}$ was synthesised where four porphyrins are attached in a different sequence and separated by an unmodified nucleotide. The drop in the melting temperature per modification in $\mathbf{5 . 8}$ is indeed only $\Delta T_{\mathrm{m}, \mathrm{P}}=-6.5^{\circ} \mathrm{C}$. In the case of the five-porphyrin array $\mathbf{6 . 9}$, no actual melting temperature could be observed, and probably no duplex is formed in this case.

The UV-vis spectra of the porphyrin-DNA strands are displayed in Fig. 2. It should be noted that, at ambient temperature,

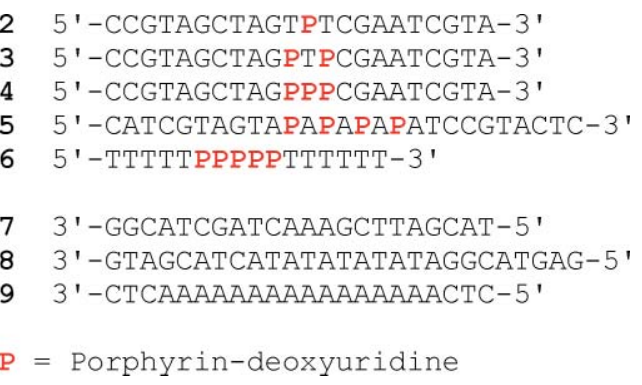

Fig. 1 Structure of the porphyrin-dU building block and ODN sequences. 
Table 1 Analytical data of 1 and of the porphyrin-DNA: melting points of the DNA duplexes and spectroscopic data of the porphyrins in the double strands

\begin{tabular}{lllll}
\hline & $T_{\mathrm{m}} /{ }^{\circ} \mathrm{C}^{a}$ & $\Delta T_{\mathrm{m}, \mathrm{P}} /{ }^{\circ} \mathrm{C}^{b}$ & $\lambda_{\max }(\log \varepsilon) / \mathrm{nm}^{a, c}$ & $\lambda_{\mathrm{em}} / \mathrm{nm}^{a}$ \\
\hline $\mathbf{1}$ & - & & $406(4.95)$ & 631,694 \\
$\mathbf{2 a} \cdot \mathbf{7}$ & 63.5 & & $412(4.60)$ & $635,657,694$ \\
$\mathbf{2 \cdot 7}$ & 42.4 & -21.1 & $386(4.00), 412(4.45)$ & $635,655,697$ \\
$\mathbf{3 \cdot 7}$ & 36.9 & -13.3 & $376(3.80), 416(4.21)$ & $636,655,697$ \\
$\mathbf{4 \cdot 7}$ & 42.2 & -7.1 & $383(4.22), 413(4.45)$ & $625,658,697$ \\
$\mathbf{5 a \cdot 8}$ & 65.0 & & & \\
$\mathbf{5 . 8}$ & 38.9 & -6.5 & $367(3.70), 418(4.01)$ & 655,714 \\
$\mathbf{6 a} \cdot \mathbf{6}$ & 42.2 & &
\end{tabular}

a Determined in $100 \mathrm{mM} \mathrm{NaCl}, 50 \mathrm{mM} \mathrm{KK_{2 }} \mathrm{PO}_{4}, \mathrm{pH} 7.0, \mathrm{c}(\mathrm{ODN})=$ $10^{-6} \mathrm{M}$. Strands $2 \mathbf{2 a}, \mathbf{5 a}$ and $\mathbf{6 a}$ are unmodified control strands. ${ }^{b}$ Decrease in $T_{\mathrm{m}}$ per porphyrin modification. ${ }^{c}$ Absorbance maxima and molar extinction coefficients determined by Gauss deconvolution.

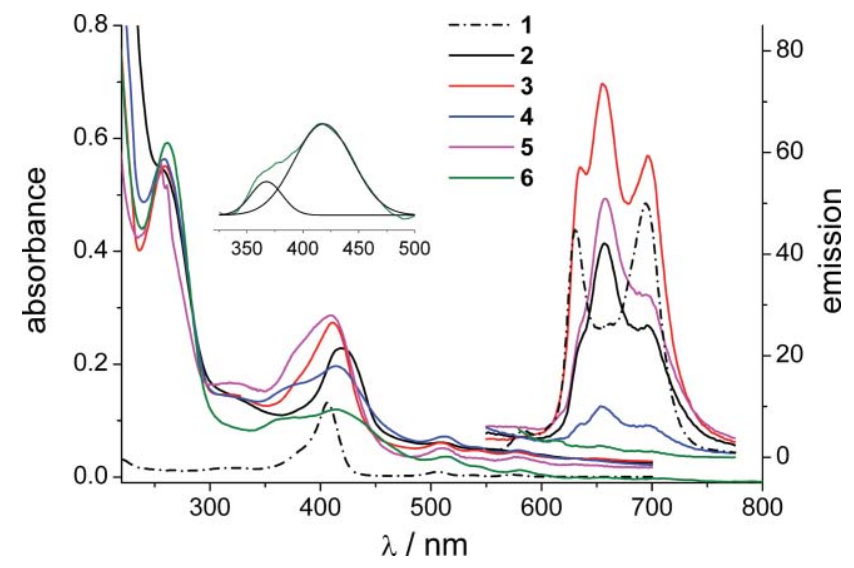

Fig. 2 UV-vis and fluorescence spectra of the porphyrin-DNA single strands. The inset shows the Gauss deconvolution of $\mathbf{6}$ as an example. $100 \mathrm{mM} \mathrm{NaCl}, 50 \mathrm{mM} \mathrm{KH}_{2} \mathrm{PO}_{4}, \mathrm{pH} 7.0, \mathrm{c}(\mathrm{ODN})=10^{-6} \mathrm{M}$.

a decrease of about $20 \%$ in the porphyrin absorbance upon duplex formation is detectable. In 2, the porphyrin B-band absorbance at $411 \mathrm{~nm}$ is broadened compared to the building block itself. In the multi-porphyrin arrays, the porphyrin absorbance becomes more and more broadened and can be deconvoluted into two overlapping absorbances. In the array $\mathbf{6}$, the absorbance is actually split into two distinguishable peaks at 367 and $418 \mathrm{~nm}$. This is characteristic of an exciton coupling between the chromophores and of stacking of the porphyrins along the DNA-scaffold.

The Soret splitting is dependent on the sequence and the amount of porphyrins in the array, and is $1422 \mathrm{~cm}^{-1}$ in $3,2302 \mathrm{~cm}^{-1}$ in 4 and $3085 \mathrm{~cm}^{-1}$ in $\mathbf{6}$ as determined by Gauss deconvolution of the absorbances (see Fig. 2, inset, for $\mathbf{6}$ as an example). The array $\mathbf{5}$, which has four porphyrins but a comparable sequence to $\mathbf{3}$ in that the porphyrins are separated by one unmodified nucleotide, shows a Soret splitting of $1688 \mathrm{~cm}^{-1}$, similar to the energy splitting in 3 . The absorbances show a relatively large blueshift and a small red-shift in the split signals compared to the single porphyrin absorbance itself. According to the point-dipole approximation of the exciton coupling model, these split signals arise from the interactions of the lower energy $B_{x}$ and higher energy $\mathrm{B}_{\mathrm{y}}$ dipoles. The shifts indicate that $\mathrm{B}_{\mathrm{y}}$ are coupled as a $J$-aggregate to give rise to the red-shifted Soret band, and $B_{x}$ are coupled as a
$H$-aggregate to give rise to the blue-shifted Soret band, respectively. ${ }^{12}$ The broadening of the signals also suggests that there is a certain freedom in orientation of the porphyrins, and they are not in a strictly fixed position. The comparable energy splitting in $\mathbf{3}$ and $\mathbf{5}$ indicate similar exciton interactions, thus the separation of the porphyrins by an unmodified nucleotide reduces the electronic coupling in the porphyrin array as compared to the neighbouring arrangement in the arrays $\mathbf{4}$ and $\mathbf{6}$, where the exciton interaction increases strongly with increasing amount of porphyrins. The strength of the exciton coupling does not change upon duplex formation with the complementary strand. This is of importance when designing porphyrin arrays that could potentially act as electronic wires.

With the point-dipole approximation and using the energy splitting of the Soret bands, the centre-to-centre distance in the porphyrins can be estimated to be $8.66 \AA$ in $\mathbf{3 . 7}, 7.38 \AA$ in $\mathbf{4 . 7}$ and $6.69 \AA$ in $6.9 . \$$ The distance of the porphyrins in $\mathbf{5 . 8}$ would be $8.18 \AA$, which is comparable to 3.7. However, according to the standard DNA model, the interchromophore distance in $\mathbf{3 . 7}$ and 5.8 would be $13.6 \AA$ (separated porphyrins), and in $\mathbf{4 . 7}$ and $\mathbf{6 . 9}$ it would be $9.74 \AA$ (adjacent porphyrins). Either the point-dipole approximation is not applicable in this case, or the chromophores are actually much closer than would be expected by the standard model. If the latter is the case, then this would indicate a large distortion in the DNA structure, which would be in agreement with the different $\mathrm{CD}$ spectra of the modified dsDNA compared to natural DNA (see below).

The exciton coupling between the porphyrins also has a strong influence on the steady state emission spectra of the arrays. The porphyrins show a very different fluorescence spectrum as compared to the building block $\mathbf{1}$. In 1, two emission maxima at 631 and at $694 \mathrm{~nm}$ with a ratio of $0.9: 1$ of the relative intensities are observed. In the porphyrin-DNA conjugates, three maxima at around 630, 660 and $700 \mathrm{~nm}$ with relative intensities of about $0.8: 1: 0.8$ can be discerned. This is quite different to what we had observed in the TPP-DNA arrays. However, a similar observation between the DPP-DNA and TPP-DNA is that the fluorescence is strongly quenched in the multiporphyrin arrays, and in $\mathbf{6}$ it is only very weak. The difference in the shape of the spectra could arise from the intramolecular stacking of the porphyrins on the DNA scaffold. No intermolecular stacking is observed and the shape of the spectra do not change in the range of 0.1 to $2 \mu \mathrm{M}$. At this point it is, however, not quite clear why the emission in $\mathbf{2}$ is also very different to 1 .

The CD spectra of $\mathbf{2 . 7}$ to $\mathbf{5 . 8}$ show the characteristic B-type DNA signature in the UV part of the spectra with a bisignate signal having maxima at $(-252) /(+277) \mathrm{nm}$ (Fig. 3). Interestingly, the signal intensity increases with increasing amount of porphyrin modification, and the duplex $\mathbf{4 . 7}$ resembles the natural DNA closest in terms of relative intensities. The porphyrin modification, therefore, has an influence on the helical structure of the DNA leading to local perturbance of the B-DNA, which could explain the large drop in thermal stability of the duplexes and the strong exciton coupling between the chromophores. Generally, the $\mathrm{CD}$ signal of the porphyrin is dominated by a broad and weak negative signal, similar to what was observed in the TPP arrays but the signals are much less intense here. A negative Soret band signal in non-covalent porphyrin-DNA complexes normally is indicative of intercalation. This feature was already 


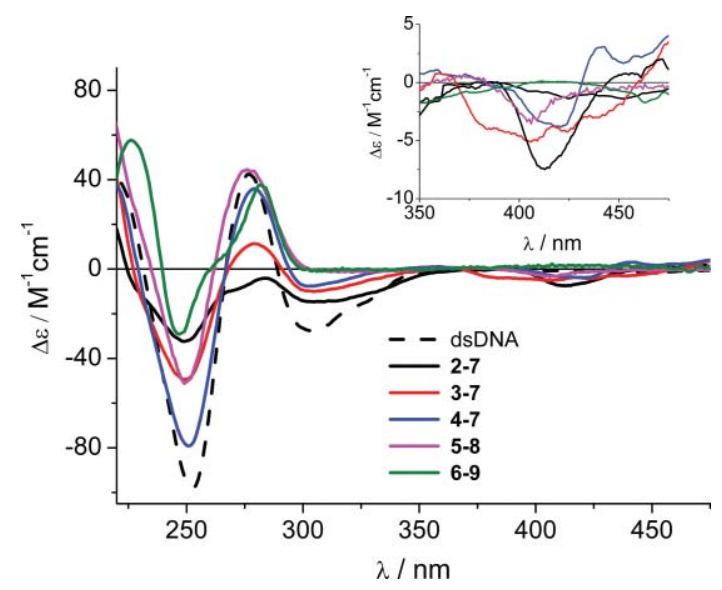

Fig. 3 CD spectra of the porphyrin-DNA duplexes. The inset shows the magnified porphyrin Soret band region.

observed in the TPP-system and discussed in detail. ${ }^{5}$ However, to demonstrate that the porphyrins are located in the major groove rather than being intercalated, we performed additional melting experiments with $\mathrm{C}-\mathrm{T}$ mismatches at the porphyrin site in the array 5.8. With four mismatches, an additional drop in $T_{\mathrm{m}}$ by $-10{ }^{\circ} \mathrm{C}$ was observed, which shows that the porphyrin bearing thymidines are still involved in Watson-Crick hydrogen bonding to the complementary nucleobase, thus the porphyrins are stacked in the major groove of the duplex.

Analogous to the TPP-DNA, in the DPP-DNA, a secondary helical structure seems to be induced in the single strands. This is concluded from the spectroscopic data obtained from the single stranded DPP-DNA at variable temperatures. In Fig. 4a and b, the spectral data for $\mathbf{5}$ as a single strand are shown as a representative example. The UV-vis, luminescence and CD spectra are similar to the spectra obtained for double stranded DPP-DNA at ambient temperature. The formation of the duplex induces, however, some quenching of the fluorescence intensity. The $\mathrm{CD}$ signals of the porphyrins are bisignate having maxima at $(+370) /(-405) \mathrm{nm}$, but are less intense for the single stranded DNA. This indicates a stable helical conformation of the single stranded DPP-DNA as compared to the random coil conformation of natural DNA. The absorbances drop by about $20 \%$ upon duplex formation, thus a more efficient stacking seems to occur after hybridisation with the complementary strand. After heating to $80^{\circ} \mathrm{C}$, the UV-vis spectra show a sharpening and increase in absorbance for the porphyrin Soret band absorption, and in the CD spectra, the Soret signal is greatly diminished. The spectra are consistent with a stacked array in the single strands at room temperature, which is disrupted at elevated temperatures. A transition can indeed be observed when the thermal denaturing of the single strands is measured at $415 \mathrm{~nm}$ where the porphyrins have their absorbance maximum (Fig. 4c). All single strands show a transition which is consistent with an unstacking of the porphyrin array. The transitions occur at increasing temperatures from 36 to $58{ }^{\circ} \mathrm{C}$ with increasing amounts of stacked porphyrins; $\mathbf{3}$ and $\mathbf{5}$ show a similar transition temperature. The spectra obtained at $80^{\circ} \mathrm{C}$ for the $\mathrm{CD}$ show that the unstacking is not complete at this temperature. The covalent linkage through the DNA thus retains a local arrangement where the porphyrins can still interact electronically even at higher temperatures.

We have also investigated the possibility of immobilising the porphyrin-DNA strands $\mathbf{2}$ to $\mathbf{4}$ on a solid phase. Synthesis of the complementary strand on an oligo affinity support was done using standard DNA synthesis. The porphyrin DNA indeed hybridises reversibly to the solid phase, leading to fluorescent beads (Fig. 5). The melting curves show a large hysteresis between the melting and the annealing, which reveals different kinetics in both processes. ${ }^{13}$ The averaged melting temperatures are quite similar for strands $\mathbf{2}$ and $\mathbf{3}$ at $48-50^{\circ} \mathrm{C}$, and much lower for $\mathbf{4}$ at $\sim 35^{\circ} \mathrm{C}$ (see the ESI:). The fluorescence spectra show similar features as obtained from a)

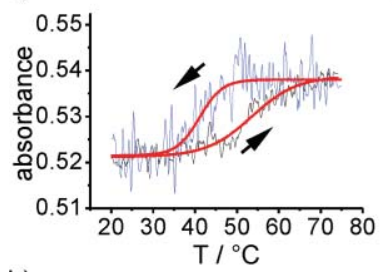

b)

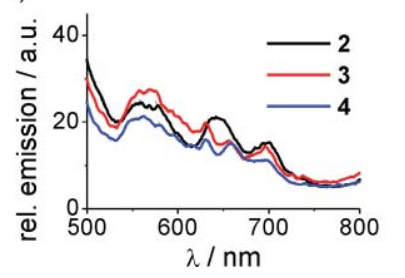

c)
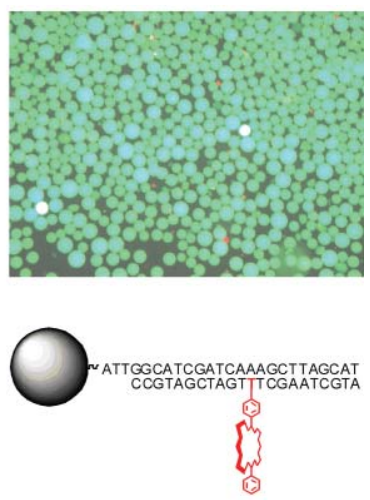

Fig. 5 Reversible binding of the porphyrin-DNA to a solid phase, performed as rapidly stirred suspensions. (a) Melting profile with sigmoidal curve fitting (2), (b) fluorescence spectra of the immobilised strands 2-4, (c) fluorescence microscopy of the porphyrin containing beads (2).
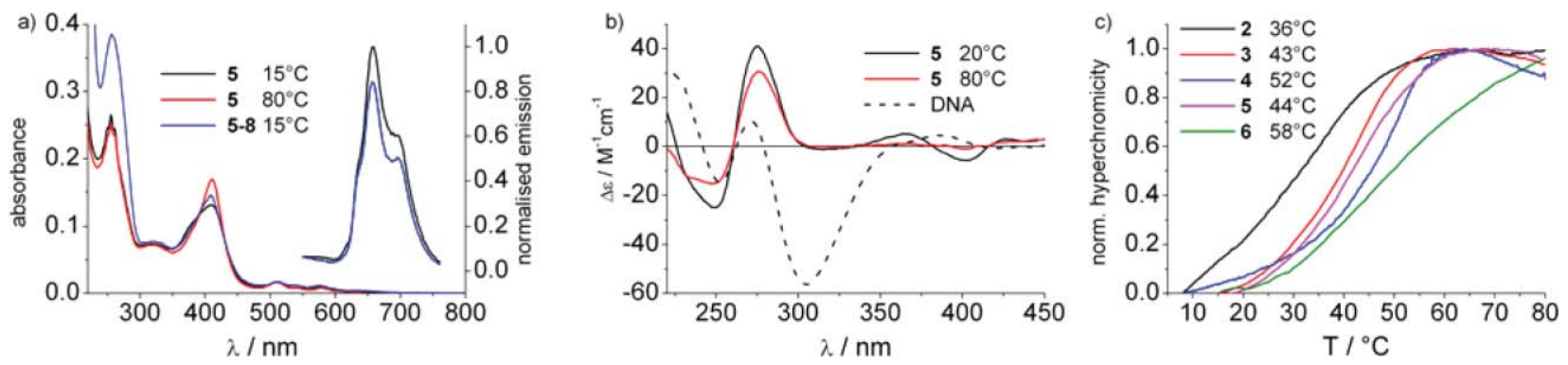

Fig. 4 (a) UV-vis absorbance and emission spectra of $\mathbf{5}$ and $\mathbf{5 . 8}$ at various temperatures; (b) CD spectra of $\mathbf{5}$ at 20 and $80{ }^{\circ} \mathrm{C}$, and of single stranded DNA; (c) normalised melting profiles of the porphyrin-DNA single strands recorded at $415 \mathrm{~nm}$, the temperatures indicate the reflection point of the curves. 
the strands in solution but with blue-shifted maxima at 565, 642 and $698 \mathrm{~nm}$ for $\mathbf{2}$. For $\mathbf{3}$ and 4, one of the emission peaks shows additional splitting with maxima at 631 and $658 \mathrm{~nm}$. The electronic coupling between the chromophores, therefore, is retained in the immobilised porphyrin arrays.

In summary, we have shown that changing the structure of the porphyrin in DNA-porphyrin arrays has a large influence on both the thermodynamic stability of the DNA duplexes as well as of the electronic properties of the porphyrins. The diphenyl porphyrin, as compared to the TPP analogue, is expected to have less steric hindrance towards neighbouring porphyrins in the array, thus closer contacts and more efficient electronic interactions are possible. This is clearly demonstrated in the large differences of the absorbance and emission spectra. However, the structure of the porphyrin-DNA arrays seems to be more disrupted than in the TPP analogous system as seen by the CD spectra and the melting measurements. These systems are in further evaluation for their applicability in energy or electron transfer through the porphyrins. DNA is indeed a very suitable scaffold to produce arrays of electronically active molecules with tunable properties, thus the synthesis of designer molecules will be achievable when combining different chromophores within the same or in complementary DNA strands.

\section{Acknowledgements}

The authors wish to thank the EPSRC for financial support, ATDbio Southampton for help in the DNA synthesis and the group of Dr Rachel O'Reilly (Cambridge, UK) for assistance in the recording of the CD spectra.

\section{Notes and references}

\$The distances of the porphyrins were calculated according to the following equation: $\Delta E=\mu^{2} / 2 \pi \varepsilon_{0} R^{3}$, where $\Delta E$ is the energy splitting $\left(\mathrm{cm}^{-1}\right), R$ is the centre-to-centre distance $(\AA)$, and $\mu$ is the transition dipole (D). $\mu$ was determined from the absorption spectrum of $\mathbf{2}$ according to ref. 14 using water as solvent $\left(n_{0}=1.333\right)$; the value obtained is $9.6 \mathrm{D}$, which agrees well with other values.

1 (a) K. M. Stewart, J. Rojo and L. W. McLaughlin, Angew. Chem., Int. Ed., 2004, 43, 5808-5811; (b) M. A. Batalia, E. Protozanova, R. B.
MacGregor, Jr. and D. A. Erie, Nano Lett., 2002, 2, 269-274; (c) S. H. Park, C. Pistol, S. J. Ahn, J. H. Reif, A. R. Lebeck, C. Dwyer and T. H. LaBean, Angew. Chem., Int. Ed., 2006, 45, 735-739; (d) G. A. Burley, J. Gierlich, M. R. Mofid, H. Nir, S. Tal, Y. Eichen and T. Carell, J. Am. Chem. Soc., 2006, 128, 1398-1399; (e) J. Wengel, Org. Biomol. Chem., 2004, 2, 277-280.

2 (a) D. Lindegaard, A. S. Madsen, I. V. Astakhova, A. D. Malakhov, B. R. Babu, V. A. Korshun and J. Wengel, Bioorg. Med. Chem., 2008, 16, 94-99; (b) M. Nakamura, Y. Murakami, K. Sasa, H. Hayashi and K. Yamana, J. Am. Chem. Soc., 2008, 130, 6904-6905; (c) D. J. Hurley and Y. Tor, J. Am. Chem. Soc., 2002, 124, 3749-3762; (d) Q. Xiao, R. T. Ranasinghe, A. M. P. Tang and T. Brown, Tetrahedron, 2007, 63, 3483-3490; (e) M. R. Reddy, N. Shibata, Y. Kondo, S. Nakamura and T. Toru, Angew. Chem., Int. Ed., 2006, 45, 8163-8166.

3 (a) A. Zahn and C. J. Leumann, Bioorg. Med. Chem., 2006, 14, 6174 6188; (b) C. Brotschi, G. Mathis and C. J. Leumann, Chem.-Eur. J., 2005, 11, 1911-1923; (c) K. Tanaka, G. H. Clever, Y. Takezawa, Y. Yamada, C. Kaul, M. Shionoya and T. Carell, Nat. Nanotechnol., 2006, 1, 190-194.

4 (a) I. Bouamaied, L. A. Fendt, M. Wiesner, D. Häussinger, S. Thöni, N. Amiot and E. Stulz, Nucleosides, Nucleotides Nucleic Acids, 2007, 26, 1533-1538; (b) I. Bouamaied, L. A. Fendt, M. Wiesner, D. Häussinger, N. Amiot, S. Thöni and E. Stulz, Pure Appl. Chem., 2006, 78, 2003-2014; (c) I. Bouamaied and E. Stulz, Chimia, 2005, 59, 101-104; (d) I. Bouamaied and E. Stulz, Synlett, 2004, 15791583.

5 L. A. Fendt, I. Bouamaied, S. Thöni, N. Amiot and E. Stulz, J. Am. Chem. Soc., 2007, 129, 15319-15329.

6 (a) M. Endo, T. Shiroyama, M. Fujitsuka and T. Majima, J. Org. Chem., 2005, 70, 7468-7472; (b) M. Endo, N. C. Seeman and T. Majima, Angew. Chem., Int. Ed., 2005, 44, 6074-6077.

7 (a) H. Morales-Rojas and E. T. Kool, Org. Lett., 2002, 4, 4377-4380; (b) E. T. Kool, Acc. Chem. Res., 2002, 35, 936-943.

8 A. Mammana, T. Asakawa, K. Bitsch-Jensen, A. Wolfe, S. Chaturantabut, Y. Otani, X. Li, Z. Li, K. Nakanishi, M. Balaz, G. A. Ellestad and N. Berova, Bioorg. Med. Chem., 2008, 16, 6544-6551.

9 (a) M. Endo, M. Fujitsuka and T. Majima, Tetrahedron, 2008, 64, 18391846; (b) M. Endo, M. Fujitsuka and T. Majima, J. Org. Chem., 2008, 73, 1106-1112.

10 R. Chinchilla and C. Najera, Chem. Rev., 2007, 107, 874 922.

11 C. Beller and W. Bannwarth, Helv. Chim. Acta, 2005, 88, 171179.

12 I. W. Hwang, M. Park, T. K. Ahn, Z. S. Yoon, D. M. Ko, D. Kim, F. Ito, Y. Ishibashi, S. R. Khan, Y. Nagasawa, H. Miyasaka, C. Keda, R. Takahashi, K. Ogawa, A. Satake and Y. Kobuke, Chem.-Eur. J., 2005, 11, 3753-3761.

13 D. A. Rusling, V. J. Broughton-Head, A. Tuck, H. Khairallah, S. D. Osborne, T. Brown and K. R. Fox, Org. Biomol. Chem., 2008, 6, 122 129.

14 H. L. Anderson, Inorg. Chem., 1994, 33, 972-981. 